\title{
Cancer Risks Related to Arsenic Waste in Georgia
}

\author{
Merab Mirtskhulava ${ }^{1,2 *}$ \\ ${ }^{1}$ National Center for Disease Control and Public Health Tbilisi, Georgia \\ ${ }^{2}$ Maxwell School of Citizenship and Public Affairs, Syracuse University, NY, USA \\ *Corresponding Author: Merab Mirtskhulava, National Center for Disease Control and Public Health Tbilisi, Georgia and Maxwell \\ School of Citizenship and Public Affaris, Syracuse University, NY, USA.
}

Received: June 17, 2019; Published: July 05, 2019

DOI: $10.31080 /$ ASMI.2019.02.0300

The purpose of the study was to determine the negative impact of arsenic waste on human health in the reagions, where industrial waste are disposed and not concerved. The research was carried out in Lechkhumi-Ambrolauri region and in Lower Svaneti - Lentekhi district of Georgia. Both Regions remains the potential threat of industrial waste exposure for region's ecology and health of local population even after the closure of industrial business.

Survey design comprised the comparison analysis of areas exposed by arsenic and those, where industrial waste was not found. Oni region, which is remoted from the disposals of arsenic industrial waste was under the target.

The survey was conducted by using the method of Cohort Study; Cohort Population was selected by considering of arsenic residues located in two districts - Ambrolauri and Lentekhi. The same size of population were selected from the neighborhood territories (Oni region), remoted from industrial waste.

Study purposed that populated areas had to be ranked by levels (high, middle and low) of arsenic waste exposure on environment. 100-100 Families living in Ambrolauri and Lentekhi were selected by the leveling methods and by considering of their health condition. Total number of household from exposed area was 600 . The same number of families was included in survey from non-exposed areas from Oni region. The whole number of target population amounted to 1200 households.

A total of 600 families in the district (many families were surveyed at non-exposed Oni region) a survey of 1200 households were involved in the 3211's and their families' health information was collected.

The survey information was collected and put in the database for analysis. The results gained after statistic analysis showed the following:
- Despite usage of sampling method (600-600 families have to be surveyed in both exposed and non-exposed regions), information about the health status in each region was different (number of family members was diverse.) $58 \%$ of information on health status was gained from total interviewed households.

- $\quad 13.7 \%$ from the total population of exposed areas was children population and $8.5 \%$ - from unexposed.

- $\quad 88 \%$ of surveyed households resided in exposed areas more than 20 years, $72 \%$ - more than 40 years, a large majority of the respondents were living in these exposure regions;

- Socio - economic status of the exposed and non-exposed population notably defers from each other. Families with monthly income of less than 200 lari in exposed areas compounds to $86 \%$, while families in non-exposured areas is $79 \%$;

- $75 \%$ of the families consume home-grown products and products bought in the local market;

- Family farms are always clean their consumption of fruits and vegetables brought in front of $89 \%$ and $87 \%$. On average, $92 \%$ of the families drinking water consumed by municipality source;

- On health self-assessment "very good"," good" and" average" positively answered $70 \%$ of the exposed population and $76.5 \%$ - of the non-exposed population. And "very poor" health condition marked $4.8 \%$ of the exposed population and $2.3 \%$ - of the non-exposed ones.

- $\quad$ Selected families from exposed and non-exposed areas who were interviewed on the relative risk of death of family members at exposed areas was $\mathrm{RR}=1,4(1,26-1,57) \mathrm{P}$-values - 0,0000000); This indicator confirms the hypothesis that population have a high incidence of death related to cancer and skin diseases and skin tumors. 
Findings and survey materials shows that various skin diseases, allergies, respiratory, endocrine, gastro-intestinal and nervous system diseases are more frequently in the population living in the areas form arsenic exposure that those living in non-exposure spots.

It's interesting, and further research needs to be exposed to a relatively high-risk areas, and other tumors of the skin, spreading it, because this is a serious study of the prevalence of cancer in an unhealthy impact on the environment.

The survey results showed the interesting findings. We think that research expansion will give us an opportunity to find correlation between the health status distribution, particularly research tumor and skin cancer high prevalence and impact of environmental exposure.

Volume 2 Issue 8 August 2019

(C) All rights are reserved by Merab Mirtskhulava. 